\title{
Ética na Pesquisa: concepção de sujeito na norma brasileira
}

Ethics on research: the subject concept in the Brazilian norm

Ética en la investigación: concepción de sujeto en la norma brasileña

\section{Maria Chalfin Coutinho}

Universidade Federal de Santa Catarina, Florianópolis, SC, Brasil.

\section{Andréa Vieira Zanella}

Universidade Federal de Santa Catarina, Florianópolis, SC, Brasil.

\section{Resumo}

Este texto, de natureza teórica, objetiva contribuir com o debate sobre a ética na pesquisa a partir da análise da concepção de sujeito que fundamenta a Resolução 196/96, principal normatização sobre ética na pesquisa com seres humanos em vigor no Brasil. A discussão dos quatro princípios norteadores dessa resolução - autonomia, não maleficência, beneficência e justiça - é feita de modo a apontar suas contradições e ambiguidades. O referencial teórico eleito para análise foi o enfoque histórico-cultural em psicologia, bem como contribuições de outros campos do conhecimento sobre as relações pesquisador/sujeito da pesquisa e algumas de suas vicissitudes. Problematizar essas relações e a legislação que orienta e regula as práticas de pesquisa, destacando suas contradições e ambiguidades, caracteriza-se como contribuição deste trabalho para a necessidade de construção de princípios éticos a serem compartilhados por pesquisadores e pesquisados, entre a comunidade científica e a sociedade de modo geral.

Palavras-chave: Ética, Investigação, Sujeito, Legislação.

\section{Resumen}

Este texto, de naturaleza teórica, objetiva contribuir con el debate sobre la ética en la investigación a partir del análisis de la concepción de sujeto que fundamenta la Resolución 196/96, principal normatización sobre ética en la investigación con seres humanos en vigor en Brasil. La discusión de los cuatro principios orientadores de esa resolución - autonomía, no maleficencia, beneficencia y justicia - se hace de modo a apuntar sus contradicciones y ambigüedades. El referencial teórico elegido para el análisis es el enfoque histórico-cultural 
en psicología, así como contribuciones de otros campos del conocimiento sobre las relaciones investigador/sujeto de la investigación y algunas de sus vicisitudes. Problematizar esas relaciones y la legislación que orienta y regula las prácticas de investigación, destacando las tensiones que las connotan, se caracteriza como contribución de este trabajo que afirma, como conclusión, la necesidad de la construcción de principios éticos a ser compartidos por investigadores e investigados, entre la comunidad científica y la sociedad de modo general.

Palabras clave: Ética, Investigación, Sujeto, Legislación.

\begin{abstract}
This theoretical text aims to contribute with the debate about ethics on research from the analysis of the subject concept that fundaments the Resolution 196/96, main valid law about ethics on research with human beings in Brazil. The debate of the four guiding principles of this resolution - autonomy, non-harm, beneficence and justice is done in order to point out its contradictions and ambiguities. The theoretical reference elected for the analysis is the historical-cultural focus on psychology, as well as contributions from other fields of knowledge about the relations between researcher and subject of the research and its variability. Questioning those relations and the laws that orientate and regulate the research practices, highlighting the tensions in them, characterizing as contribution of this study that concludes the need of creating ethic principles to be shared by researchers and subjects of research, between the scientific community and society as a whole.
\end{abstract}

Key-words: Ethics, Research, Subject, Laws. 
Introdução

As discussões sobre ética na pesquisa vêm ganhando fôlego nos últimos anos, motivadas por acontecimentos vários, como os casos de plágio em trabalhos acadêmicos; a clonagem de mamíferos; o transplante de células tronco; as exigências dos periódicos científicos de que os autores, quando do encaminhamento de trabalhos para publicação, apresentem documentação comprobatória da aprovação das pesquisas por comitês de ética; entre outros.

No Brasil, o caso das investigações com células tronco, incluídas na Lei de Biossegurança (lei 11105 aprovada em março de 2005), envolveu amplo debate dentro e fora do Congresso Nacional, tanto por ocasião de sua aprovação como, posteriormente, quando sua constitucionalidade foi julgada e aprovada no Supremo Tribunal Federal em 2008. A mobilização da mídia e, na sua esteira, da opinião pública para tal debate foi intensa, embora não necessariamente marcada pela ciência de sua dimensão ética.

No campo das artes esse debate também esteve próximo do público brasileiro em 2005, com "O Jardineiro Fiel", premiado filme dirigido pelo cineasta Fernando Meirelles. O interessante deste filme, além da bela fotografia e sua qualidade como um todo, é a temática abordada, a saber, a questão da utilização de seres humanos como cobaias em pesquisas de indústrias farmacêuticas. Esse fato, não necessariamente novo posto que a polêmica há muito vem sendo levantada e denunciada, formal ou informalmente, ganhou visibilidade no Brasil para além dos espaços acadêmicos uma vez transformado em roteiro da sétima arte.

Mas se a opinião pública vem sendo mobilizada para a reflexão sobre as relações entre ética e ciência mais recentemente, na esfera acadêmica $o$ debate é antigo. O tema abordado no filme - o uso de cobaias humanas em experimentos clínicos com vistas ao desenvolvimento de novos fármacos e combate a doenças, particularmente em pesquisas financiadas por laboratórios farmacêuticos - é presente no circuito acadêmico desde a polêmica em torno do Estudo Tuskegee (nome do centro de saúde onde foi desenvolvido), realizado entre as décadas de 1930 e 1970 (Guilhem \& Diniz, 2008). Com o objetivo de conhecer o ciclo natural de evolução da sífilis, os participantes foram divididos em dois grupos: aqueles que receberam o tratamento para doença e o grupo controle, que não recebeu nenhum tratamento, nem mesmo a penicilina, principal antibiótico descoberto no período. 
O primeiro documento elaborado com a preocupação de proteger eticamente participantes de pesquisas foi o Código de Nurembergue, surgido a partir do famoso julgamento dos crimes de guerra cometidos pelos nazistas na segunda guerra mundial e, de certo modo, contemporâneo ao estudo desenvolvido em Tuskegee. Entretanto, de acordo com Guilhem e Diniz (2008), não há uma incorporação imediata dos princípios do Código de Nurembergue às práticas de pesquisa. Inspirada nos preceitos éticos deste código, a Associação Médica Mundial propôs, em 1964, a Declaração de Helsinque. Essa declaração, que passou por diversas revisões desde sua primeira edição, propõe intervir diretamente na prática de pesquisa biomédica e torna-se referência fundamental para todas as regulamentações envolvendo questões relativas à ética na pesquisa com seres humanos (Diniz \& Corrêa, 2001; Guilhem \& Diniz, 2008). O documento destaca o direito dos sujeitos investigados às informações sobre os objetivos da pesquisa e os seus resultados, bem como a necessidade de que declarem por escrito que participam da pesquisa de livre e espontânea vontade, podendo desistir dessa participação em qualquer momento.

Se a Declaração de Helsinque data da década de 60, no Brasil a primeira legislação que regulamenta a pesquisa com seres humanos é aprovada duas décadas depois, pelo Conselho Nacional de Saúde (CNS): trata-se da Resolução 1/88, modificada em 10 de outubro de 1996, com o estabelecimento da Resolução 196, principal normatização sobre ética na pesquisa com seres humanos em vigor no país (Guilhem \& Diniz, 2008).

A Resolução 196/96 toma como referência o código de Nürembergue (1947), a Declaração dos Direitos do Homem (1948) e a Declaração de Helsinque (1964 e versões posteriores), além de outras legislações nacionais e diretrizes nacionais e internacionais. Desde então, as instituições que desenvolvem pesquisas com seres humanos têm procurado se adequar a essa legislação, sendo o efeito mais visível a criação de comitês específicos para a análise de projetos de pesquisa e emissão de pareceres sobre os aspectos éticos envolvidos.

A partir dessa Resolução (196/96), foi institucionalizado no Brasil um sistema para controle e acompanhamento das pesquisas com seres humanos, com vistas a sua adequação às normas ali previstas resolução e em outras resoluções complementares, posteriormente estabelecidas. Trata-se do Sistema CEP/CONEP, composto pelos Comitês de Ética em Pesquisa (CEPs) e pela Comissão Nacional de Ética em Pesquisa (CONEP) - 
vinculada ao Conselho Nacional de Saúde (CNS) do Ministério da Saúde.

A vinculação ao CNS e, principalmente, os parâmetros biomédicos que pautam as normatizações e o Sistema CEP/CONEP têm sido objeto de debate no campo acadêmico, particularmente por pesquisadores do campo das ciências sociais e humanas (ver, entre outros: Oliveira, 2004; Poli, 2006; La Taille, 2008). Outro fator a suscitar controvérsias no campo tem sido a tentativa de transformar as normas sobre ética de pesquisa com seres humanos em lei existem hoje tramitando no Congresso Nacional projetos nesse sentido.

O principal Projeto de Lei sobre o tema em tramitação, PL 2473/2003 ${ }^{1}$ de autoria do Deputado Colbert Martins, é detalhado e se propõe a transformar em lei a Resolução 196/96, estabelecendo inclusive a criminalização de condutas consideradas como não adequadas aos parâmetros estabelecidos.

O III Encontro Nacional dos Comitês de Ética em Pesquisa, realizado em junho de 2010, foi palco para o debate relativo aos PLs que estão em tramitação no Congresso Nacional. Há o temor de que a aprovação do PL 2473/2003 implique na extinção Sistema CEP/CONEP, o que significa o fim do Controle Social: conforme declaração do presidente do CNS, Francisco Batista, com a lei "as decisões serão tomadas apenas no âmbito do legislativo, o que engessará o processo e impedirá adequações que dependem de debates e avaliações periódicas"².

Apesar da importância do debate, as implicações éticas das pesquisas são bem mais complexas do que a legislação prevê e das práticas sociais instituídas pelos comitês que a controlam. Tal complexidade pode ser observada em várias instituições nas quais a manutenção de um comitê de ética único vem se apresentando como um problema para a comunidade científica, posto a dificuldade em avaliar projetos de áreas distintas e considerar as diversidades metodológicas que, por sua vez, apresentam questões éticas igualmente distintas.

Estudiosos de diversos campos das ciências humanas têm debatido o sistema de controle social hoje em vigência no Brasil. Se a própria Resolução 196/96 é objeto de polêmica, sua transformação em lei, sem a devida escuta da comunidade acadêmica e de toda a sociedade certamente agravaria o problema. No campo da Psicologia várias entidades científicas têm participado deste debate, entre as quais a Associação Nacional de Pesquisa e Pós-Graduação em Psicologia (ANPEPP). A ANPEPP conta com uma comissão específica e tem realizado debates sobre o tema da ética na pesquisa em seus simpósios bianuais. No último 
simpósio, realizado em junho de 2010, esta associação lançou um manifesto sobre a regulamentação da ética na pesquisa com seres humanos, conclamando a ampliação do debate e chamando pesquisadores e sociedades científicas de diferentes áreas. $\mathrm{O}$ manifesto faz eco às muitas vozes que reverberam o tema, ao afirmar sua preocupação "com o engessamento, a criminalização e a eliminação do controle social do sistema de regulamentação da ética na pesquisa que envolve seres humanos, transferindo este controle para a área judicial"3.

Considerando este quadro de dificuldades e controvérsias, é objetivo deste texto contribuir com o debate sobre o tema a partir da análise da concepção de sujeito na qual a Resolução 196 se sustenta. O referencial teórico eleito para discutir a questão é o enfoque históricocultural em psicologia, bem como contribuições de outros campos do conhecimento sobre as relações pesquisador/sujeito da pesquisa e algumas de suas vicissitudes. Destacamos ainda, como introdução ao debate, que, em nosso entendimento, falar em ética na pesquisa implica ter como metas de toda investigação - compartilhadas entre pesquisadores e pesquisados, entre a comunidade científica e a sociedade de modo geral - a dignidade humana, o compromisso com a vida, com o seu desenvolvimento e complexificação. Essas são condições necessárias à existência, tanto pessoal como coletiva, e se apresentam como eixo norteador das discussões aqui apresentadas.

\section{A Resolução 196/96 e a Concepção de Sujeito que a Fundamenta}

A Resolução 196/96 é um documento longo, organizado em 10 seções, desde o preâmbulo até as disposições transitórias, que tratam de temas como: os aspectos éticos da pesquisa envolvendo seres humanos, o consentimento livre e esclarecido, riscos e benefícios, a estruturação dos protocolos de pesquisa e a organização de um sistema nacional de apreciação dos protocolos de pesquisa, composto pelos comitês locais das instituições de pesquisa (CEPs) e pela Comissão Nacional de Ética em Pesquisa (CONEP), ligada ao Ministério da Saúde.

Um aspecto fundamental para $o$ entendimento desta Resolução diz respeito à necessidade de anuência dos sujeitos, ou seus representantes legais, em participar da pesquisa. Tal anuência implica na concordância formal em ser participante da investigação, a qual somente poderá ser iniciada após a assinatura de um documento intitulado Termo de Consentimento Livre e Esclarecido (TCLE). 
O TCLE é o documento fundamental em todo protocolo de pesquisa a ser avaliado pelo comitê de ética na pesquisa (CEP) da instituição onde a investigação será realizada. Após a aprovação do protocolo, a pesquisa se inicia com a assinatura do TCLE pelos participantes ou seus representantes legais. Desta forma, estaria assegurado o respeito à dignidade dos sujeitos-participantes e garantida assim a sua autonomia, bem como a defesa dos grupos considerados vulneráveis ou legalmente incapazes. Mas onde se assenta essa crença no respeito à dignidade?

Já em seu preâmbulo a Resolução 196/96 afirma incorporar “...sob a ótica do indivíduo e das coletividades, os quatro referentes básicos da bioética: autonomia, não maleficência, beneficência e justiça, entre outros, e visa assegurar os direitos e deveres que dizem respeito à comunidade científica, aos sujeitos da pesquisa e ao Estado"4. Esses quatro referentes básicos, que aqui vamos denominar de princípios, são norteadores de toda a Resolução ${ }^{5}$.

A problemática da tentativa de normatização das atividades de pesquisa pode ser condensada nos seus princípios, palavras-signos essencialmente polissêmicas: a que se referem, ou melhor, quais os sentidos acolhidos para essas palavras? O que há de presumido no supostamente dito?
Qualquer reflexão sobre as diretrizes estabelecidas nessa Resolução deve partir de um questionamento sobre esses quatro princípios que a norteiam, bem como sobre em que medida o sujeito pode ser livre para optar pela participação em uma dada investigação. Interessa-nos aqui debater o tema tendo como referência pesquisas nas ciências humanas, em particular na Psicologia, considerando as relações estabelecidas entre pesquisadores e sujeitos e as concepções de sujeitos que as norteiam.

Inicialmente cabe questionar qual sentido de autonomia a Resolução comporta. Esta pode ser vista como "... a capacidade de se autogovernar", remetendo-se, quando se considera a perspectiva individual, ao “...direito de um indivíduo de tomar decisões livremente; independência moral ou intelectual" (Houaiss \& Villar, 2001, p. 351). Autonomia é, portanto, um conceito diretamente relacionado ao de liberdade, pois é livre quem é "...senhor de si e de suas ações; dotado de poder de escolha" (idem, p.1773). Tanto uma quanto a outra definição pressupõem um sujeito descolado das condições históricas e sociais que determinam as suas possibilidades e impossibilidades de escolha, ou seja, como entidade distinta, separada, única. 
$\mathrm{O}$ sentido que se coletivizou, denominado por Vygotsky (1992) como significado, e geralmente descrito nas palavras frias de um dicionário, tenta estancar o fluxo constante das palavras e, na sua esteira, da própria realidade. A partir do resgate das contribuições do psicólogo francês F. Pauhlan, Vygotsky (1991, p. 333) destaca que “(...) o sentido da palavra é a soma de todos os sucessos psicológicos evocados em nossa consciência graças à palavra. O significado é só uma dessas zonas do sentido, a mais estável, coerente e precisa". Sentido pressupõe uma clara separação entre indivíduo e sociedade, entendidos como polos dicotômicos que estabelecem interação, mas que seguem, cada qual, um determinado rumo, rumo este que, no caso da pessoa, depende unicamente de sua vontade e de suas escolhas. Entendidos como esferas separadas, temos no sentido dicionarizado uma compreensão de indivíduo que destitui da complexidade do real e do modo como a pessoa com este se relaciona as explicações para os modos de ser e viver. Temos, enfim, a afirmação da a-historicidade e a negação da dialética das relações sociais como constituintes da própria humanidade e de cada pessoa em particular.

Contrapondo-se a essa noção que destitui da história e de seu movimento a responsabilidade sobre as (im)possibilidades humanas, Vygotsky afirma a historicidade do humano e seu caráter relacional, na medida em que afirma que cada pessoa é "um agregado de relações sociais encarnadas num indivíduo" (Vygotsky, 2000, p. 33). Depreende-se daí que só há sujeito porque constituído em contextos sociais, os quais, por sua vez, resultam da ação concreta de pessoas, coletivamente organizadas em seu próprio viver. Desse modo, apresenta-se a indissociabilidade de sujeito e sociedade, pois "Apenas na coletividade (de uns e outros) é que cada indivíduo encontra os meios de desenvolver suas capacidades em todos os sentidos; somente na coletividade, portanto, torna-se possível a liberdade pessoal" (Marx \& Engels, 1989, p.117).

Aceitar esta relação de mútua constituição, ao tornar indissociáveis o que aparentemente se distancia - sujeito e sociedade - não significa, por sua vez, negar a possibilidade de afirmação de singularidades: ao contrário, complexifica a sua compreensão, pois significa que autorregulação da conduta e vontade, ícones da autonomia e da liberdade, somente são possíveis via apropriação das ferramentas semióticas disponíveis no momento histórico em que se vive. Em outras palavras, “...qualquer processo volitivo é inicialmente social, coletivo, interpsicológico" (Vygotsky, 1996, p. 113), ou seja, toda e qualquer ação é 
instituída a partir das condições sociais tornadas próprias pelas pessoas e que continuam sendo sociais.

Decorre da condição inexoravelmente cultural do ser humano que a autonomia do sujeito, se é um fato, precisa ser entendida de forma relativa, posto que o sujeito é datado e, necessariamente, marcado pelas condições reais e concretas do contexto sócio histórico do qual ativamente participa. A esse respeito Morin afirma: "O indivíduo é, pois, um objeto incerto. De um ponto de vista, é tudo, sem ele não há nada. Mas, a partir do outro, não é nada, se eclipsa. De produtor converte-se em produto, de produto em produtor, de causa torna-se efeito, e vice-versa. Podemos, assim, compreender a autonomia do indivíduo, mas de uma maneira extremamente relativa e complexa" (Morin, 1996, p. 48).

A relativização do que vem a ser autonomia e liberdade $^{6}$, pautada no reconhecimento de que cada pessoa só o é na relação com outras, parece não encontrar guarida na Resolução 196/96. Afinal, ao se referir à consulta aos sujeitos da pesquisa, esta é apresentada sem menção às complexas relações de poder que se instituem entre pesquisador e sujeito da pesquisa, tampouco às efetivas condições de escolha dessas pessoas que, por sua vez, são decorrentes de suas condições culturais, socioeconômicas, de suas motivações e vontade, igualmente fundadas nas tramas do coletivo.

Cabe observar que a resolução prevê casos nos quais ocorrem restrições à liberdade e à capacidade de esclarecimento, necessárias para o adequado consentimento às pesquisas. Entre esses casos é possível destacar a situação de crianças e adolescentes ou outros sujeitos "em situação de substancial diminuição de suas capacidades de consentimento"; "sujeitos que, embora adultos e capazes, estejam expostos a condicionamentos específicos ou à influência de autoridade"; ou ainda aqueles inseridos "em comunidades culturalmente diferenciadas, inclusive indígenas", entre outros.

O reconhecimento destas restrições à liberdade mostra que a própria norma já aponta para limitações no que tange a generalização dos princípios por ela estabelecidos. Afinal, quem são os adolescentes que precisam solicitar aos pais autorização para participar de uma pesquisa científica? Qual a idade em que uma pessoa deixa de ser criança ou que ainda não é considerada como adulta? As respostas não são simples e muito menos consensuais, pois dependem da pessoa sobre a qual se fala e das relações estabelecidas, por ela, com os muitos outros com os quais convive. Os questionamentos sobre adolescência 
repercutem nos meios de comunicação de massa com cada vez maior frequência, com a veiculação de notícias tanto sobre adolescência precoce quanto tardia. Assim, caberia também questionar se se trata de solucionar o problema por meio de mudanças na faixa etária dos considerados como capazes de se responsabilizarem por si mesmos. Ao contrário, a realidade mostra que as classificações precisam ser problematizadas e questionadas - afinal, há cada vez mais exceções à regra - e o olhar para cada pessoa em sua concreta condição de existência se torna axiomático para toda e qualquer intervenção, sendo a pesquisa considerada também como um modo de intervir.

Importante destacar que, dependendo da pesquisa, consideramos, certamente, prudente manter a solicitação de autorização dos pais ou responsáveis, como quando são utilizados procedimentos invasivos ou algum tipo de medicamento. Porém, em pesquisas na área de ciências humanas, principalmente na antropologia, na sociologia e na psicologia social, onde as observações e entrevistas se apresentam como procedimento privilegiado de coleta de informações, necessita o jovem solicitar aos pais que assinem essa autorização? Jovens de 16 anos, que podem votar em eleições majoritárias? Jovens que, apesar de menores de 18 anos, são pais e engrossam as estatísticas sobre maternidade/paternidade precoce? Há muitas outras situações vivenciadas por pesquisadores que de certa forma questionam aspectos da Resolução 196/96. Mais especificamente, há uma contradição de base nessa exigência de autorização pelos pais ou responsáveis, a qual não raro inviabiliza a própria investigação, pois o projeto de dar voz ao jovem é tutelado à voz de um terceiro, legalmente responsável por aquele.

Ser legalmente responsável, por sua vez, é outra questão complexa, pois não significa necessariamente que os responsáveis exerçam as atividades que lhes são socialmente imputadas nas relações com os dependentes. Não cabem exemplos aqui, mas estes são fartos nos documentos de Conselhos Tutelares ou Serviços de atendimento à infância e adolescência.

Continuando a problematização, há que se perguntar quem são os "sujeitos que, embora adultos e capazes, estejam expostos a condicionamentos específicos ou à influência de autoridade". Ora, estar sob a "influência da autoridade" é uma expressão muito abrangente, afinal quem não estaria sob este tipo de influência? Ainda que exaustiva, a lista dos sujeitos nestas condições apontados na resolução ${ }^{7}$ não dá conta da totalidade dos sujeitos constrangidos por condições de existência 
e subsistência cada vez mais precárias no contexto contemporâneo.

A lista referida parece apontar apenas aquelas pessoas inseridas em organizações como escolas, prisões, empresas, abrigos etc., como se o poder fosse exercido apenas nos locais com autoridade formalmente estabelecida, não se espalhando por redes de relações sociais, políticas e econômicas. Como exemplo, é possível destacar entre os sujeitos sob constrangimento da autoridade listados na resolução os empregados, uma inclusão certamente pertinente, haja vista as diferentes formas de assédio as quais se encontram submetidos; mas, e os desempregados e os trabalhadores informais, será que esses não estão também sob condicionamentos? E quanto aos próprios convidados a participarem como sujeitos de pesquisas, há que se considerar o lugar social ocupado por eles em suas relações com o próprio pesquisador. Há diferentes lugares de saber/poder que demarcam as posições de um e outro, e desconsiderar isso significa cegar-se para vieses interpretativos, os quais podem, ao invés de contribuir para a compreensão de uma realidade que é necessariamente complexa, simplificá-la.

Para além dessas situações, que certamente se multiplicam, nos parece fundamental pensar sobre mecanismos sociais, presentes nas sociedades contemporâneas, que propiciam a ilusão de um indivíduo livre e autônomo. Sánchez, Martinez e Rico (2006) analisam as implicações da implantação de políticas neoliberais para os sujeitos, estimulando-os a serem participantes ativos de suas vidas, preservando a autonomia e a iniciativa dos governados. Desta forma, cada indivíduo seria capaz de buscar "livremente" sua felicidade e realização pessoal. "Paradoxalmente, a autonomia pessoal não é a antítese do poder político, senão um elemento fundamental para o seu exercício" (idem, p. 9-10, tradução das autoras).

Além da autonomia, a Resolução 196/96 estabelece também os princípios relativos à beneficência e a não maleficência, os quais reportam, respectivamente, a praticar o bem e a evitar o mal. Nessa perspectiva, deve-se buscar tudo o que for positivo, pautando-se em “...princípios referentes à vida e à dignidade das pessoas, preconizados como propícios ao desenvolvimento e ao aperfeiçoamento moral, quer dos indivíduos, quer da comunidade" (Houaiss \& Villar, 2001, p. 429). Do mesmo modo, agir de forma a evitar o mal implicaria em não fazer "...o que prejudica ou fere; o que concorre para o dano ou ruína de alguém ou de algo, desastroso para a felicidade ou bem-estar físico ou moral” (idem, p.1816). 
Complexifica-se aqui nossa análise, pois saímos do campo da ética, da reflexão sobre os modos de ser da coletividade, e adentramos na esfera da moral, ou seja, das regras ou costumes adquiridos por hábito. Aí é mister perguntar: de que bem e mal se fala? Bem ou mal para quem? Quem assume qual pólo nas relações pesquisador (e seus financiadores) e pesquisados? Para superar perspectivas maniqueístas, é necessário suplantar a noção de bem e mal pela noção do que é bom ou mau para a vida, do que promove ou avilta a existência humana, de que modo, em que medida.

Se tomarmos os princípios da beneficência e maleficência como metas, não morais, mas éticas, como algo a ser atingido, não é possível negar que as pesquisas devem se pautar sempre na defesa da vida, em suas diferentes manifestações, e no repúdio à violência. Entretanto, a mesma Resolução 196/96 afirma que “...toda pesquisa envolvendo seres humanos envolve risco", definindo como risco de pesquisa a "possibilidade de danos à dimensão física, psíquica, moral, intelectual, social, cultural ou espiritual do ser humano, em qualquer fase de uma pesquisa ou dela decorrente.” Esta definição expõe uma contradição presente na Resolução, pois a admissão de risco sempre presente é incompatível com a busca da beneficência e não maleficência, ainda que considere a maximização dos benefícios e a minimização de danos e riscos. Retoma-se a pergunta: O que é bem (ou do bem) e o que é mal (ou do mal)? Bem ou mal para quem? Quais as relações de poder que se apresentam nas práticas de pesquisa e quais os interesses em jogo?

Além do mais, se considerarmos as práticas de pesquisa no campo da psicologia e de outras ciências humanas, a noção de um risco sempre presente parece pouco pertinente, principalmente se levarmos em conta os procedimentos para coleta de informações geralmente utilizados (como entrevistas, questionários, observações etc.). Tais procedimentos podem ser considerados como pouco invasivos, “...quando comparadas àquelas com fármacos ou novas terapêuticas" (Guilhem \& Diniz, 2008, p. 38) ou mesmo anódinos, embora sempre se possa considerar inexistência de "risco zero" (La Taille, 2008, p.275).

O último princípio norteador da Resolução em análise é o relativo à justiça, que pode ser entendida como “...caráter, qualidade do que está em conformidade com o que é direito, com o que é justo...”. Considera-se justo o que ocorre “... conforme à justiça, à eqüidade, à razão" (Houaiss \& Villar, 2001, p. 1696).

A busca da justiça trata-se de um princípio amplo, o qual, ao longo da Resolução, aparece geralmente associado à ideia de um direito coletivo. Desta forma, 
pode-se destacar da Resolução: a importância da "relevância social" e a “destinação sócio-humanitária" da pesquisa; o respeito aos valores das comunidades envolvidas; retorno dos benefícios obtidos com a pesquisa às comunidades; comunicação às autoridades dos resultados, quando estes puderem contribuir para as condições de saúde da coletividade, entre outros. Aqui é importante destacar que a consonância entre o princípio da justiça e a coletividade, muito mais como uma meta a ser alcançada do que como um elemento regulador inicial, se coloca como um pressuposto fundamental para uma ética coletiva da pesquisa com seres humanos, para uma ética que se apresenta como uma estética da existência, o que necessariamente “...não deve ser visto como uma atitude solitária, particular, mas, sim, como um empreendimento coletivo, solidário" (Gallo, 1997, p.108). Afinal, somos o que somos porque sempre em relação, sendo os outros o fundamento da possibilidade do que se é e do que se pode vir a ser $^{8}$.

\section{Considerações finais}

A análise aqui desenvolvida sobre a concepção de sujeito que fundamenta a Resolução 196/96, em particular em seus princípios norteadores, revela uma visão na qual o ser humano é sempre portador de autonomia e liberdade. Conceber o sujeito autônomo e livre como algo dado, ou seja, como uma condição previamente estabelecida - pois conforme determina a Resolução 196/96, a pesquisa só tem início após o consentimento informado significa imputar apenas ao próprio sujeito as condições para sua liberdade e autonomia. Mas como pensar o sujeito descolado das relações sociais que o instituem como humanidade, como singular e coletivo, como identidade e diferença?

Somos, todos e qualquer um, sujeitos de e sujeitados a um determinado tempo, espaço e lugar. Nesse sentido, as condições, sejam quais forem, não são responsabilidade só de um ou alguns, mas sim de todos, posto que se apresentam como histórica e culturalmente constituídas, como resultado das formas pelas quais coletivamente são organizados os modos de viver e de ser, inexoravelmente complexos e marcados pelas características do momento em que se vive, das suas condições históricas de possibilidades e do que pode vir a ser.

Estas condições, por sua vez, são (re)produzidas nas relações pesquisadorpesquisado ao longo do processo de investigação, posto que aí se objetivam lugares de saber-poder característicos da lógica cultural da qual são partícipes e ao 
mesmo tempo artífices, autores e personagens. Problematizar essas relações, necessariamente tensas e atravessadas por interesses, motivações e necessidades várias, é condição para investigações que partem do reconhecimento da historicidade das relações humanas e investem nas possibilidades de que estas possam se apresentar como relações éticas-estéticas, criadoras, comprometidas com a própria vida.

O compromisso com a própria vida e o questionamento das relações entre pesquisador e pesquisado implicam repensar a concepção de pesquisa presente na Resolução 196/96, a qual ao desconsiderar “... as particularidades de cada ciência e de cada método - ou seja, assumindo de modo acrítico a definição positivista de ciência - incorpora e impõe a todos os pesquisadores o modelo biomédico de pesquisa" (Poli, 2006, p. 10). Entre as estratégias para repensar nosso modo de investigar compartilhamos com perspectiva adotada por Oliveira (2004) de realizar pesquisas com seres humanos e não $e m$ seres humanos.

No caso da pesquisa em seres humanos, a relação com os sujeitos, objeto da pesquisa, tem como paradigma uma situação de intervenção, na qual esses seres humanos são colocados na condição de cobaias... Já no caso da pesquisa com seres humanos, o sujeito de pesquisa deixa a condição de cobaia (ou objeto de intervenção) para assumir o papel de ator (ou de sujeito de interlocução) (Oliveira, 2004, p.33/34 - grifos do autor).

Cabe ainda observar que durante o desenvolvimento de uma pesquisa, cujo protocolo foi aprovado inicialmente por um comitê de ética, não existem garantias de que não surgirão problemas éticos. Nossa experiência como pesquisadoras revela justamente o oposto, e o enfrentamento desses problemas requer atenção constante para o que acontece no campo e suas implicações. Tal postura, por sua vez, requer a reinvenção permanente do próprio pesquisar de modo a que a ética de bons encontros com os outros com os quais se pesquisa possa ser viabilizada.

Por sua vez, o número cada vez maior de investigações em curso tende a dificultar o acompanhamento das atividades de pesquisa pelos comitês de ética. Assim, caberia repensar o papel destes comitês considerando o caráter formativo, ao invés de fiscalizador, que podem assumir. Permanecendo como agentes fiscalizadores, correm o risco, como alerta La Taille (2008), de se perderem na constante reelaboração de regras e formas de controle e, em consequência, prestando um desserviço à discussão dos aspectos éticos presentes em toda e qualquer investigação. 
Em razão da urgência do debate sobre esses aspectos, duas possíveis alternativas precisam ser analisadas: uma alternativa consiste na ampliação do espectro de atuação desses comitês de ética para além das intenções de pesquisadores, através do acompanhamento mais detalhado das pesquisas em curso. Para tanto, as condições de trabalho nesses comitês precisam ser revistas, bem como a proposição e análise de estratégias para essa empreitada, nem um pouco simples. Outra alternativa, que não exclui a anterior e se apresenta, na verdade, como seu fundamento, é a abertura de espaços permanentes, na própria comunidade de pesquisadores, para discussões sobre a temática e a análise de suas decorrências, contribuindo, assim, para a formação ética dos pesquisadores e o envolvimento no debate.

\section{Notas}

${ }^{1}$ Além do PL 2473/2003, existe na Câmara Federal uma proposta substitutiva ao mesmo, elaborada por sua relatora, a Deputada Cida Diogo, que conta com apoio de integrantes do CNS. No Senado Federal tramita o PL 78/06, de autoria do Senador Cristovam Buarque, que estabelece punições e co-responsabilidades para violações das normas relativas a pesquisa com seres humanos (fonte: Audiência Pública $\quad$ CNS <http://conselho.saude.gov.br/ultimas_noti cias/2010/14_abr_audiencia_pub.htm> - acesso em 02/03/2011.

${ }^{2}$ Fonte: CNS - Deputados não participam de debates sobre projetos de sua autoria. <http://conselho.saude.gov.br/ultimas_noti cias/2010/22_jun_projeto.htm> - acesso em 02/03/2011.

3 Fonte: ANPEPP (2010) Manifesto de Fortaleza

〈http://www.anpepp.org.br/XIIISimposio/ Manifesto\%20de\%20Fortaleza.pdf> acesso em 02/03/2011.

${ }^{4}$ Os trechos entre aspas, sem identificação de fontes, foram retirados da resolução 196/96, disponível em <http://conselho.saude.gov.br/web_comiss oes/conep/aquivos/resolucoes/resolucoes.ht $\underline{\mathrm{m}}>$

${ }^{5}$ De acordo com Guilhem e Diniz (2008) a teoria dos quatro princípios ou teoria principialista, na qual se assenta toda ética biomédica, teve como inspiração original o Relatório Belmont, publicado em 1978. Esse relatório foi elaborado pela Comissão Nacional para Proteção dos Sujeitos Humanos em Pesquisas Biomédicas e Comportamentais, instituída pelo governo dos Estados Unidos, e propôs três princípios norteadores da ética em pesquisa: respeito pelas pessoas, beneficência e justiça. 
${ }^{6}$ Os questionamentos sobre autonomia e liberdade são aqui apresentados, conforme já assinalado, a partir da vertente histórico-cultural em psicologia. Outros autores fazem tais questionamentos em consonância com outras vertentes, como por exemplo Poli (2006) e La Taille (2008).

${ }^{7}$ Ver item VI.3 da Resolução 196/96.

${ }^{8}$ Sobre a temática constituição do sujeito a partir da perspectiva histórico-cultural, ver Zanella (2005).

\section{Referências}

Diniz, D. \& Corrêa, M. ( 2001) Declaração de Helsinki: relativismo e vulnerabilidade. Cadernos de Saúde Pública, 17 (3), 679-688.

Gallo, S. (coord.) (1997) Ética e cidadania: caminhos da filosofia. Campinas/SP: Ed. Papirus.

Guilhem, D. \& Diniz, D. (2008) O que é ética em pesquisa. São Paulo/SP: Brasiliense (Col. Primeiros Passos).

Houaiss, A. \& Villar, M. A. de S. (2001) Dicionário Houaiss de Língua Portuguesa. Rio de Janeiro/RJ: Objetiva.

La Taille, Y. (2008) Ética em pesquisa com seres humanos: dignidade e liberdade. Em: I. C.

Marx, K. \& Engels, F. (1989) A Ideologia Alemã (Feuerbach). São Paulo:
Hucitec, $7^{\mathrm{a}}$ Edição. (tradução de original alemão publicado em 1973)

Morin, E. (1996) A noção de sujeito. Em: D. F. Schnitman, (Org), Novos Paradigmas, Cultura e Subjetividade (pp.45-58). Porto Alegre/RS: Artes Médicas.

Oliveira, L. R. C. de (2004) Pesquisa em versus pesquisas com seres humanos. Em: C.

Poli, M. C. (2006) O sujeito na ciência: questões à bioética. Psicologia \& Sociedade, 18 (3), 7-15.

Sánchez, L. G.; Martínez, L. M.; Rico, F. J. (2006) Psicologia, identidade e política nas tecnologias de poder neoliberais. Psicologia \& Sociedade, 18 (1), 7-14.

Víctora; R. G. Oliven; M. E. Maciel \& A. P. Oro (Orgs), Antropologia e ética: o debate atual no Brasil (pp. 33-44). Niterói/RJ: EdUFF.

Vygotsky, L. S. (1991) Obras Escogidas II: pensamiento y lenguaje. Madrid: Visor Distribuiciones S.A. (tradução de original russo publicado em 1982) Zanella, A. V. (2005) Sujeito e alteridade: reflexões a partir da psicologia histórico-cultural. Psicologia \& Sociedade, 17 (2), 99-104.

Z. Guerreiro; M. L. S. Schimidt, \& Zicker, F. (Orgs.), Ética nas pesquisas em ciências humanas e sociais na saúde 
(pp. 268-279). São Paulo: Aderaldo \& Rot.

Maria Chalfin Coutinho. Professora do Departamento de Psicologia e do Programa de Pós-Graduação em Psicologia da Universidade Federal de Santa Catarina, Brasil e bolsista em produtividade do CNPq.

E-mail: chalfin@mbox1.usfc.br

Andréa Vieira Zanella: Professora do Departamento de Psicologia e do Programa de Pós-Graduação em Psicologia da Universidade Federal de Santa Catarina, Brasil e bolsista em produtividade do CNPq.

E-mail: azanella@cfh.ufsc.br 